\title{
O PRINCÍPIO DE RAZÃO, O UTILITARISMO E O ANTIUTILITARISMO*
}

Alain Caillé

Resumo. Neste artigo, procura-se demonstrar que as noções de razão utilizadas nas ciências sociais são largamente determinadas pela tradição utilitarista e que, por conseguinte, na prática, o conceito de racionalidade tem limites discutíveis dados pela subordinação do mesmo à questão do cálculo interessado. Mas a crítica à racionalidade utilitarista é complexa na medida em que existem diferentes registros do utilitarismo: o prático, como é o caso do utilitarismo economicista que prega a satisfação primeira de interesses egoístas materiais; o teórico, que propõe serem todos os homens egoístas e calculistas por natureza; e o normativo, que vincula o ideal de justiça à satisfação do maior número de indivíduos. A crítica às teses utilitaristas leva o autor a lembrar a contribuição de Marcel Mauss na fundação de um novo paradigma, o da dádiva. Enfim, este texto é fundamental para se compreender a passagem de uma crítica antiutilitarista negativa para uma outra, antiutilitarista positiva, que se apoia na criação do novo paradigma.

Palavra-chave: utilitarismo, racionalidade, dádiva, Marcel Mauss.

Em que medida o destino das ciências sociais está ligado ao do princípio de razão? Em que medida, por outras palavras, o seu acesso à cientificidade, que elas tanto dizem procurar, implica que admitam a hipótese de a ação humana e social obedecer, pelo menos na sua parte mais significativa, a uma causalidade racional? Se tentar dar a esta pergunta uma resposta puramente empírica, parecerá desde logo que, na atividade concreta dos investigadores em ciências humanas e sociais,

Alain Caillé é diretor do GEODE (Grupo de Estudos e Observação sobre Democracia) da Uni versidade de Nanterre e editor da Revue du M. A. U. S. S.

* Publicado anteriormente como o capítulo 4 do livro A Demissão dos Intelectuais: a Crise das Ciências Sociais e o Esquecimento do Factor Político (Lisboa : Instituto Piaget), este texto retoma, completando-a, uma comunicação apresentada em 24 de novembro de 1990 durante o Colóquio Bentham, em Genebra. Mantivemos a sua forma oral, mas introduzimoslhe notas muito substanciais que o leitor mais apressado poderá saltar. 
o princípio de razão se limita a desempenhar um papel menor. Os historiadores não se pronunciam sobre isso. Com exceção, bastante rara, dos que se deixaram influenciar pela teoria econômica neoclássica, os etnólogos não procuram em geral imputar cálculos racionais aos seus primitivos ou aos seus selvagens prediletos, mesmo que lhes reconheçam a capacidade de enunciar proposições bem formadas. A maior parte do trabalho sociológico atual tenta dissimular a ausência de esqueleto teórico determinado da disciplina, sacrificando ao imperativo descritivo ou entregando-se às delícias da interrogação intermediável do sentido da ação. Tanto num caso como no outro, a hipótese de racionalidade não tem aplicação.

Mas este primeiro ponto de referência é demasiado grosseiro e não capta o essencial. Entenda-se: se se limita o ideal da cientificidade ao empirismo, se ele renunciou desde logo a toda a procura das causas, das determinantes ou das razões da ação social, então, e justificadamente, não há qualquer necessidade de acrescentar a hipótese de racionalidade. Mas, como já sugerimos, as ciências humanas e sociais (CHS) não podem contentar-se indefinidamente com descrever ou "compreender". Devem igualmente explicar, isto é, procurar causas para efeitos e estabelecer normas, isto é, interrogar-se sobre a desejabilidade dos efeitos. De modo que o quadro muda de alto a baixo logo que se vira o olhar para o lado das disciplinas ou das escolas que visam à sistematicidade ou, simplesmente, à coerência teórica. Aí, a hipótese da racionalidade, quer seja manejada sob a sua forma fraca ou sob a sua forma forte, parece incontornável. Forma fraca, a que se limita a afirmar o caráter determinante para a ação das necessidades, das utilidades, das preferências ou dos interesses. Forma forte, a que postula, além disso, que estes últimos são mais ou menos objeto de um cálculo consciente e explicitável, e se ordenam segundo essa transitividade que constitui, aos olhos dos teóricos, a marca sem equívocos da racionalidade. A ciência econômica desenvolve-se inteiramente a partir da tomada a sério desta versão forte, de que ela entende tirar todas as conseqüências e separar todas as implicações. Mesmo os economistas que se mostram mais críticos face ao simplismo da figura do Homo ecconomicus, e que são sensíveis à complexidade, para não dizer à indeterminação do critério de racionalidade, como acontece em França com os recentes economistas das convenções, torcem o nariz ao rompimento com o individualismo metodológico, ou seja, em definitivo, com o postulado da racionalidade 
dos indivíduos, como se, ao pô-lo em causa, o chão ameaçasse fugirlhes debaixo dos pés. ${ }^{1}$

Referência ao social a isso obriga, e a Sociologia ficou durante muito tempo acantonada na esfera do funcionalismo ou do estruturofuncionalismo, imputando a fonte primeira da racionalidade a um hipotético sujeito coletivo, a sociedade ou o sistema.

Depois começou também a namoriscar com o individualismo metodológico, o mais das vezes, é verdade, sob uma forma particularmente débil e desprendida. Nos anos 70 e em França especialmente, no ponto alto da voga estruturalista, acreditava-se que a Lingüística e, na sua esteira, a Semiótica poderiam oferecer à teoria econômica uma alternativa isenta de pressupostos racionalistas. A questão de saber o que subsiste hoje das esperanças teóricas depositadas, durante algum tempo, na Lingüística, não é clara. E a das relações que ela mantém com a hipótese de racionalidade ainda menos. O racionalismo cartesiano de Noam Chomsky, mesmo que prima facie tivesse pouco a ver com o racionalismo dos economistas, não era menos maciço. E o movimento que fez deslizar o interesse principal dos lingüistas da fonologia para a gramaticalidade e desta última para o discurso, para a pragmática, para os atos de linguagem e para as interações verbais, acabou por trazer ao primeiro plano o princípio de razão.

Se o sentido da palavra, que explica "o que quer dizer falar", se identifica com os interesses de poder e com a reivindicação de uma legitimidade social determinada, se ele depende da "pertinência" que, por sua vez, depende das "necessidades" dos locutores, ${ }^{2}$ se, além disso, é suposto que os atos de palavra valem proporcionalmente à exigência de validade universal de que seriam portadores, nesse caso é claro que, forte ou fraca, a hipótese de racionalidade está toda presente no centro da atividade da Lingüística contemporânea. E, quanto à teoria analítica da ação, que se desenvolve nos confins da filosofia da linguagem, da filosofia social e da teoria do direito, na esperança de "ocupar o lugar de uma metateoria comum às teorias empíricas da ação, à ética e à filosofia social, à teoria da decisão, etc." (Neuberg, 1991, p. 9), ela põe no centro da sua atividade a reflexão sobre os paradoxos co-extensivos ao princípio de razão, dado que "só um ser racional pode ser irracional" (Davidson, 1991, p. 21). 
Façamos um resumo para dar uma primeira resposta à nossa pergunta inicial. Se a maior parte dos investigadores em CHS continua indiferente ao princípio de razão, em contrapartida, os que aspiram à teoria parecem ter dificuldade em dispensá-lo. Em muitos aspectos, este estado de fato não deixa de ser desconcertante. Na sua versão forte, com efeito, a hipótese de racionalidade não procede de nenhum fundamento empírico determinado, chegando mesmo a vangloriar-se disso. Resume-se numa proposta tautológica que enuncia, como o notava já no século XIX o historiador MaCaulay, que os sujeitos humanos são racionais na medida em que preferem o que preferem. A teoria econômica é um gigantesco floreado tecido à volta desta lapalissada. O floreado revela um belo objeto intelectual, a teoria do equilíbrio geral. Mas, tirando o prazer que oferece à contemplação, as suas potencialidades explicativas preditivas são, no melhor dos casos, duvidosas. ${ }^{3}$ Construída sobre uma coluna empírica ausente, precisaria de mais que um toque de varinha mágica para reencontrar afinal, o solo empírico que julgou dispensável à partida.

A versão fraca do princípio de razão, a que privilegia a força dos interesses, é mais suscetível de pertinência empírica. Mas convém notar que esta virtude empírica é, na maior parte das vezes, completamente virtual, e é, em todo o caso, independente do próprio princípio de razão. O que nos importa, de fato, não é que nos afirmem que os sujeitos humanos têm interesses ou preferências, coisa de que ninguém duvida, mas que nos digam em que consistem esses interesses e preferências num dado período histórico ou numa dada situação social, e como se articulam com a exigência de desinteresse, enunciada vigorosamente por todas as morais e todas as religiões. O princípio de razão não tem, como tal, nenhum elemento de resposta para dar a estas questões, porque a sua circularidade lógica o impede de amoedar o seu esplendor abstrato em moeda empírica miúda. Comparando a incrível massa de trabalhos inspirados pela hipótese de racionalidade com os fracos resultados obtidos e utilizáveis, é difícil deixarmos de concluir que algo vai mal no reino das CHS. O fracasso deve-se, pensamos, a duas razões fundamentais interligadas.

Não vamos ocupar-nos aqui da primeira causa da falência teórica das ciências sociais. Ela é inerente ao seu próprio projeto de teorizar, de acordo com o modelo em vigor nas ciências exatas. ${ }^{4}$ Se o recurso ao 
princípio de razão parece legitimado pela idéia de que ele não é mais que uma ciência do previsível, então temos de estar em condições de prever a ação social e de assumir o direito de o fazer, convindo ainda postular que a ação resulta das previsões dos sujeitos e neles se esgota no essencial.

A segunda causa, mais difícil de confirmar, tem duas opções. Por um lado, pode-se pensar que, se os teóricos em CHS persistem neste ponto, numa via que só lhes traz sucessos mitigados e em larga medida imaginários, é porque a atração exercida pelo princípio de razão tem menos a ver com as suas capacidades explicativas, que são fracas ou nulas, do que com a sua carga normativa. O princípio não serve tanto para descrever o mundo histórico e social tal como é, como para o mostrar tal como deveria ser. Um dos melhores teóricos da ação racional conclui significativamente: "O ser humano é um animal racional no sentido em que aceita a racionalidade como norma". ${ }^{5}$ É a carga ética ligada ao princípio de razão que explica, pode-se pensar, o seu sucesso junto dos teóricos, e a inconsciência, largamente espalhada, dessa carga ética que explica o fracasso das suas teorias. Por outro lado, e este segundo aspecto da hipótese terá ainda mais dificuldades em convencer o nosso leitor, esta junção de uma ambição teórica puramente abstrata, fundada no fantasma da previsibilidade da ação, e de uma mensagem normativa ligada ao mesmo fantasma, tem um nome e ocupa um lugar eminente na história do pensamento ocidental: é nem mais nem menos que o utilitarismo.

\section{Utilitarismo e modernidade}

Como esta última afirmação não deixará de surpreender e parecerá intempestiva ou excessiva, será útil explicar rapidamente como chegamos à sua formulação. E é tanto mais útil na medida em que, se o utilitarismo é bem conhecido dos filósofos anglo-saxônicos, a ponto de por muito tempo lhes parecer que era estreitamente co-extensivo à filosofia moral, resumindo-a, ele é praticamente desconhecido dos intelectuais franceses ou, em sentido mais amplo, "continentais". Devemos, contudo lembrar que nem sempre foi assim. O empirismo moral anglo-saxônico era objeto, na França, no fim do século XIX, de discussões muito vivas e perfeitamente informadas, especialmente por parte de Jean-Marie Guyau 
(1985) e de Élie Halévy (1903). Bérgson refere-se-lhe também, com precisão, em Les deux sources de la Morale et de la Religion. E, na Alemanha, Max Scheler (1971) discute-o em pormenor em Nature et formes de la sympatie, a ponto de fazer dele o seu adversário teórico principal. Não esqueçamos, igualmente, que é também o utilitarismo, na sua forma spenceriana, que Durkheim e Mauss contestam prioritariamente. Mas este passado teórico está hoje quase totalmente esquecido, e filósofos franceses e continentais ignoram tudo dos desenvolvimentos trazidos ao utilitarismo filosófico desde Henry Sidgwick, e fingem acreditar que os problemas que eles levantam estão há muito resolvidos. Nós próprios não fugíamos a este esquecimento e a este desconhecimento quando, irritados pela explosão de racionalismo economista que atingiu as ciências sociais nos anos 70, decidimos, com alguns economistas, antropólogos e sociólogos, fundar um "Movimento antiutilitarista nas ciências sociais", agrupado à volta de um Boletim, mais tarde a Revue du MAUSS (Éditions La Découverte).

Quando escolhemos este nome, é justo reconhecer que tínhamos uma idéia muito vaga e escolar do utilitarismo. O nome surgiu como que por acaso, para homenagear Marcel Mauss. Por utilitarismo entendíamos simplesmente o economismo, cuja crítica pretendíamos iniciar na esteira de Marcel Mauss e de Karl Polanyi. Ou ainda, por utilitarismo não designávamos muito mais que aquilo que estigmatiza o senso comum ou o que Durkheim vituperava na Sociologia e na Economia Política anglo-saxônicas. Diga-se, em nossa defesa, que os manuais de história do pensamento filosófico, econômico e político praticamente não atribuíam nenhum lugar significativo nem a Jeremy Bentham, nem aos seus predecessores, nem aos seus sucessores. Ao longo dos anos, contudo, fomos tomando cada vez mais a sério o rótulo antiutilitarista e, portanto, o próprio utilitarismo. A ponto de, pelo menos no que me diz respeito, reconhecer ao utilitarismo um lugar cada vez mais preponderante na história do pensamento ocidental. Com efeito, pareceme agora possível afirmar, ou pelo menos admitir, a hipótese segundo a qual o utilitarismo constitui o alicerce do pensamento ocidental ou, mais geralmente, de todo o pensamento "moderno", i. e., de todo o pensamento que rompeu com o fundamento religioso e tradicionalista. Que ele é, em suma, o resultado espontâneo e principal do recurso ao princípio de razão. 
Claro que se trata de uma afirmação que exige numerosos comentários, explicações e esclarecimentos. Por agora, proponho que se entenda por utilitarismo a conjunção de duas propostas: uma proposta teórica e uma proposta normativa. A proposta teórica enuncia que a ação humana e social resulta dos cálculos racionais de sujeitos interessados, quer sejam individuais ou coletivos, egoístas ou altruístas (a hipótese dominante é a do egoísmo). A proposta normativa, por sua vez, defende que são justas ou virtuosas as ações, as normas ou as leis que concorrem para maximizar a felicidade dos sujeitos assim definidos e, se possível, de todos esses sujeitos ou, pelo menos, do maior número deles. Para apreender o sentido desta caracterização da modernidade pela dominância do utilitarismo, deve-se confrontá-la com outras caracterizações. A tradição sociológica põe em cena toda uma série de oposições, entre o estatuto e o contrato, entre as sociedades militares e as sociedades industriais, entre a solidariedade mecânica e a solidariedade orgânica, entre a Gemeinschaft e a Gesellschaft, todas resumidas pela oposição operada por Louis Dumont entre holismo e individualismo. Por seu lado, a tradição filosófica pensa a modernidade sob o signo da matematização do mundo, da dominância do princípio de razão e do esquecimento do ser, ou também, com Hegel, sob o signo da subjetividade. As caracterizações mais satisfatórias, de resto muito próximas, são, a meu ver, as de Louis Dumont (pelo individualismo) e de Hegel (pelo subjetivismo). Mas exigem esclarecimentos, sob pena de se confundir tudo e mais alguma coisa. Por um lado, sociedades igualmente individualistas ou subjetivistas podem revelar-se muito dissemelhantes, mesmo incomensuráveis. Com efeito, segundo Louis Dumont, o nazismo ganha raízes no terreno do individualismo. Ora, está claro que não se pode defender uma identidade entre uma sociedade nazi, fascista, comunista ou liberal.

Para não misturar tudo convém pois, no mínimo, distinguir que conforme as sociedades, igualmente individualistas ou subjetivistas nos seus princípios, se fundamentam imaginariamente nas paixões dos indivíduos ou nas suas previsões. Aliás, não se deve hipostasear e dar a entender que toda a modernidade seria unificada na sua dependência em relação com uma essência única e homogênea de que representaria a emanação.

Isso leva a precisar o estatuto da hipótese. Ela não pretende minimamente que todo o pensamento moderno seria utilitarista, bem 
pelo contrário, mas que o campo histórico desse pensamento é o das tentativas, abortadas, de refutar a banalidade de base utilitarista. $\mathrm{O}$ pensamento moderno desdobra-se no campo de um confronto entre inteligibilidade utilitarista, a mais natural e a mais espontânea a partir do momento em que rompeu com a religião, e as múltiplas tentativas de refutação. Se o utilitarismo continua a ser dominante, é porque nenhuma dessas tentativas de o refutar ou de o ultrapassar conseguiu cristalizarse num paradigma alternativo suficientemente claro, explícito, e partilhado pelo conjunto dos pensadores, para se tornar suscetível de produzir um saber cumulativo e uma normalidade partilhada. É evidente que, para arriscar uma formulação, uma hipótese de uma tal generalidade, é impossível contentarmo-nos com um conceito de utilitarismo tão rudimentar com aquele a partir do qual o MAUSS se estruturou inicialmente.

\section{Os três registros do utilitarismo}

Parece assim necessário, por razões de maior clareza e de precisão, distinguir três registros do utilitarismo: o do utilitarismo prático, o do utilitarismo teórico (ou cognitivo), e, finalmente, o do utilitarismo normativo (ou filosófico), apresentando-se cada um destes três registros segundo, pelo menos, duas modalidades, ou mesmo três, possíveis, a do utilitarismo sofisticado (ou distinto), vulgar e economicista. Por utilitarismo prático designo simplesmente o que o sentido corrente entende quando estigmatiza os calculadores interessados. O utilitarismo prático sofisticado é o que calcula, com vistas a realizar interesses superiores, por exemplo religiosos ou altruístas. O utilitarismo vulgar é o que só persegue interesses egoístas. O utilitarismo economicista é aquele que procura a satisfação de interesses egoístas materiais.

O utilitarismo teórico, por seu lado, repousa sobre a hipótese de que os homens são efetivamente sujeitos egoístas, independentes e calculistas. Esta hipótese constitui, a meu ver, a hipótese de base das ciências sociais. Chamemos-lhe a axiomática do interesse. O utilitarismo normativo ou filosófico, finalmente, defende que é justo ou virtuoso o que contribui para a maximização da felicidade de todos ou do maior número. Em Critique de la raison utilitaire (1989), que resumia o trabalho efetuado pelo MAUSS entre 1981 e 1988, tentei uma 
especificação e uma crítica dos dois primeiros utilitarismos, prático e teórico, mas pequei ao não dar um tratamento específico ao utilitarismo normativo. Aqui, gostaríamos de: 1) resumir rapidamente o que foi dito em Critique de la raison utilitaire sobre esses dois primeiros utilitarismos, consagrando depois algum tempo a: 2) expor a antinomia da razão utilitária normativa para, num terceito tempo, 3) sugerir que a via para ultrapassar o utilitarismo teórico e normativo passa por uma continuação da reflexão eboçada por Marcel Mauss, no seu Essai sur le don.

\section{O utilitarismo prático e o utilitarismo teórico}

1) Sobre o utilitarismo prático, não é necessário gastar muito tempo. Contentamo-nos em anotar três idéias:

O utilitarismo prático, por outras palavras, o cálculo interessado, existe em todas as sociedades, incluindo as mais arcaicas, mas está geralmente subordinado a uma exigência antiutilitarista. Numa palavra, existe mas não é legítimo.

A especificidade das sociedades modernas reside na legitimação do utilitarismo vulgar e, mais precisamente, na do utilitarismo economicista. O momento decisivo desta legitimação é, como sugeriu Max Weber, constituído pela Reforma. Mas esse trabalho da legitimação da procura dos interesses materiais começa muito antes. Em Florença, já em finais do século XIV e começos do século XV se explica que a realização do amor de Deus e do próximo passa pelo enriquecimento material. ${ }^{6}$

O outro grande momento forte neste processo de legitimação do utilitarismo prático vulgar e economicista é representado pelas teorias do contrato social, e especialmente pelas de Hobbes e de Locke, que entendem fundar as sociedades modernas a igual distância do poder do Papa ou do poder do imperador, unicamente na fruição pacífica dos bens materiais. Até há bem pouco tempo, em todas as sociedades modernas, o utilitarismo prático manteve-se de algum modo equilibrado, contrabalançado por um princípio antiutilitarista, por exemplo, a religião nos Estados Unidos ou a ética do serviço público na França. 
Em contrapartida, desde a Segunda Guerra Mundial e, mais precisamente, desde os anos 70, o utilitarismo prático economicista generaliza-se e não é contido por nenhuma paliçada. Nada lhe resiste. Nesta incapacidade de imaginar um freio ao utilitarismo vulgar economicista podemos ler, creio, os sinais de uma certa falência das ciências sociais e da filosofia moral e política.

2) O utilitarismo teórico (ou, se se preferir, a axiomática do interesse), o que tenta explicar a ação humana pelos cálculos egoístas dos indivíduos ou dos grupos, está já bem presente no pensamento antigo, onde, contudo, não é ainda verdadeiramente dissociado das preocupações normativas e da interrogação do bem. De igual modo, nas teorias jusnaturalistas ele continua subordinado à procura das normas da justiça. É só com o nascimento das ciências sociais e, mais precisamente, com o nascimento da Economia Política - digamos em 1776 - que ele se emancipa do discurso filosófico e da preocupação moral, para se apresentar sob aspectos puramente científicos, se por ciência entendermos a procura de propostas cognitivas que sejam totalmente independentes das propostas normativas.

Durante dois séculos, as ciências sociais desenvolvem-se no seio de um campo de pensamento dominado pelo utilitarismo da Economia Política, mas equilibrado e contrabalançado pela preocupação antiutilitária trazida pela Sociologia e pela Antropologia, quando, todavia, elas não se limitam a opor um utilitarismo coletivista ao utilitarismo individualista dos economistas. A Economia Política afirma que os sujeitos sociais são egoístas amorais, e que o egoísmo amoral, por intermédio do mercado, essa máquina para transformar os vícios privados em virtudes públicas, é a condição da justiça e da felicidade coletivas. Em graus diversos, a Sociologia e a Antropologia consistem numa crítica dessas afirmações que caracterizam a figura do Homo ecconomicus.

Em 1960, contudo, paralelamente à alforria generalizada do utilitarismo no domínio da prática, o pensamento das ciências sociais balança, por sua vez, num utilitarismo generalizado. Com Gary Becker, a Economia Política, agora rebatizada de Ciência Econômica, sai das suas fronteiras e pretende explicar a totalidade da ação social. Os sociólogos acreditam neste imperialismo da Economia Política e imitam- 
na. As sociologias de Pierre Bourdieu ou de Raymond Boudon por exemplo, na França, apresentam-se como economias políticas generalizadas. ${ }^{7}$ Também nos Estados Unidos, sob a denominação de teoria da ação racional, a corrente dominante em Sociologia é a que se inspira na modelização econômica. ${ }^{8}$ Certamente que existem muitas outras correntes de pensamento nas ciências humanas e sociais que as correntes de inspiração utilitarista; por exemplo, as correntes empiristas, hermenêuticas, etnometodológicas, comparativistas, etc. Mas nenhuma dessas correntes consegue verdadeiramente, em nossa opinião, suplantar o utilitarismo, porque nenhuma consegue ligar propostas teóricas e propostas normativas.

Não tentaremos demonstrar aqui as razões porque este utilitarismo (aliás, individualismo metodológico, teoria da escolha racional, etc.) é insatisfatório. Limitemo-nos a salientar dois pontos:

- Ele defende como um universal antropológico o que não passa do imaginário próprio da modernidade.

- É maciçamente tautológico e auto-refutante.

Uma vez que desenvolvi estas críticas noutro lugar, é tanto menos necessário retomá-las aqui quanto é certo que se inicia, de forma evidente nos nossos dias, uma autocrítica deste utilitarismo teórico generalizado. No centro da própria ciência econômica, especialmente na seqüência dos trabalhos de Herbert Simon, a noção de racionalidade revela-se cada vez mais obscura, e ninguém, hoje, acredita verdadeiramente que seja possível deduzir as normas sociais dos cálculos instrumentais dos indivíduos. ${ }^{9}$ Ao mesmo tempo, desenvolveu-se nos Estados Unidos, a partir de 1988, uma poderosa corrente crítica qualificada de socioeconomicista, ${ }^{10}$ tendo por base o reconhecimento explícito das insuficiências do modelo neo-clássico. Salientemos, aliás, que em diferentes esferas do saber sentem-se os frêmitos que anunciam o nascimento de um esforço interacionista, preocupado em evitar os escolhos tanto de um holismo como de um individualismo duros e dogmáticos. Contudo, mantém-se em aberto a questão de saber onde se poderia operar esta ultrapassagem interacionista. Quanto a mim, penso que ela pressupõe uma crítica explícita e sensata do utilitarismo, que assuma não só os seus objetivos teóricos, mas sobretudo, as suas apostas normativas, porque a força do utilitarismo, em última instância, não 
reside tanto, como se disse, nas suas capacidades explicativas, que são fracas, como no seu propósito normativo e filosófico.

\section{A crítica das teorias da ação racional}

Depois de passar em revista o conjunto das teorias da ação racional, Paul K. Moser (1990, p. 9), na introdução a um volume que reúne os textos essenciais na matéria, conclui: "Traditional decision theory can not plausibly be thougt to give us an uncontroversial account of rational action". Distingamos dois grandes blocos de teorias da ação racional.

1. As que argumentam, a partir da hipótese de que as preferências (as necessidades, as utilidades ou os interesses, pouco importa) são dadas, "paramétricas", e que as possibilidades alternativas e o futuro são conhecidos do sujeito. Ou elas recusam pronunciar-se sobre a natureza das preferências (etc.), e nesse caso são puramente tautológicas (um sujeito é racional na medida em que prefere o que prefere); ou tentam pronunciar-se sobre o conteúdo das preferências (etc.), mas nada de plausível foi alguma vez enunciado na matéria e continuamos a ignorar se, e em que medida, os sujeitos humanos agem por interesse (egoísta ou altruísta, econômico, social ou simbólico), por prazer, por obrigação, espontaneamente, etc. De qualquer maneira, para julgar das preferências ou dos interesses, seria necessário dispor dos critérios de segunda linha, julgar em nome de meta-preferências. O que nos leva ao segundo bloco de teorias da ação racional.

2. É o bloco das teorias que defende que as preferências não são dadas ne varietur, paramétricas, mas estratégicas, i. e. dependentes das escolhas dos outros sujeitos (ver Elster, 1979), que a informação não é perfeita e que a racionalidade é, por isso, limitada (ver Simon, 1982), que o futuro é incerto, aberto ao risco. Neste caso, a racionalidade depende de fatores puramente idiossincrásicos e afetivos, dado que não existem critérios racionais que permitam decidir se é melhor visar um ganho máximo provável (minimax), minimizar as perdas possíveis (maximin), ou outras escolhas. E, se as preferências já não são consideradas como dadas, em nome de que escolher as preferências que seria preferível ter? Em nome de preferências de segunda linha, diz- 
nos, por exemplo, Harry Frankfurt (1971, traduzido em M. Neuberg et al., p. 253-269). Mas, em nome de que julgar estas metapreferências? A pouco e pouco, verifica-se que os critérios de racionalidade dependem do simbolismo coletivo e das regras de moral, de que a teoria das escolhas racionais entendia fazer a Economia, ou que ela projetava deduzir escolhas racionais individuais. Esta aporia é perfeitamente posta a claro por toda a literatura consagrada ao dilema do prisioneiro, que teve dificuldade em deixar de concluir que seria mais racional não o ser, ou antes, que é mais racional ser moral que racional ("Morality is an essential part of maximization”, conclui David Gauthier, 1986).

De maneira mais geral, todos os debates à volta da racionalidade nos parecem marcados por uma dupla confusão: entre lógica e racionalidade, por um lado, e, por outro, entre causas e razões (entre o que Albert Schutz chamava os weil motiven e os um zu motiven, entre o porquê e o para quê).

Sejamos justos, esta distinção entre causas e razões está no centro da obra de Donald Davidson. Mas, como não se combinou à primeira, parece-nos que conduz a obscuridades. Em casos raros, quando todos os dados de um problema são identificados, quando não há ambigüidade sobre o jogo em que ele é jogado, é admissível que se decida se uma ação é lógica ou não. De um ponto de vista analítico, a idéia de racionalidade nada traz à idéia de logicidade. A sua utilização tem, por isso, finalidades propriamente metafísicas. Permite que se ponha em cena o fantasma de sujeitos que seriam, de parte a parte e integralmente lógicos, em todas as suas esferas de atividade, lógicos na articulação das suas lógicas parcelares, autoprodutores e transparentes por si mesmos no cálculo lógico ou aritmético. A imagem alucinatória de uma tal homogeneidade lógica, enraizada na certeza calculante, denega desde logo a divisão dos sujeitos entre pólos irredutíveis da ação, do interesse, do prazer, da obrigação e da espontaneidade, e a sua divisão entre o que faz sentido para eles (os um zu motiven, o para quê) e as suas determinantes objetivas (os weil motiven, o porquê). Tudo isto é comprovado por toda a literatura sobre os paradoxos da irracionalidade, que acaba sempre na divisão do sujeito. Em conclusão: é a própria noção de racionalidade que é insensata, simples metáfora laicizada da imagem do deus onisciente e onipotente. Não tem sentido que um sujeito queira 
ser racional. Em contrapartida, ele pode esforçar-se para ser sensato, mais isso é outra história.

\section{O utilitarismo filosófico ou normativo}

Suponhamos que relevam do utilitarismo filosófico - ou normativo - as doutrinas que enunciam que são justas, e só elas, as ações, as normas e as leis que contribuem para a maximização da felicidade do maior número de indivíduos, preocupados em maximizar a diferença positiva entre os prazeres e os sofrimentos. Ou, ainda, se se escreve J = Justiça, $\mathrm{Ui}=$ Utilidade do indivíduo, nesse caso o utilitarismo normativo gravita à volta da equação segundo a qual $\mathrm{J}=\operatorname{Max} \sum$ Ui. Notemos, de passagem, que o critério utilitarista da justiça é de ordem holista. O problema que se levanta a seu propósito é o de saber qual a relação que existe entre o justo, assim definido no plano do coletivo e a virtude ou a utilidade dos indivíduos. A virtude será equivalente ao que concorre para a maximização da utilidade da soma dos indivíduos ou só para a maximização da utilidade individual, e a própria utilidade individual será função da justiça ou independente dela? As diversas escolas utilitaristas diferenciam-se em função:

- Da maneira como articulam J (justiça), V (virtude) e Ui;

- Da resposta que dão à questão de saber quem calcula, racionalmente, o sujeito individual, empírico ou transcendental, o legislador racional, o coletivo, ou Deus.

Gostaria de tentar aqui: 1) Definir o lugar desta formulação utilitarista no conjunto da Filosofia Moral e Política; 2) Iniciar uma crítica do utilitarismo filosófico, mostrando que ele tropeça numa antinomia fundamental.

\section{1) O lugar do utilitarismo normativo na Filosofia Moral e Política}

De qualquer modo, oficialmente designa-se por utilitarismo a doutrina de Jeremy Bentham e dos seus discípulos, quase todos anglosaxões, John Stuart Mill, Henry Sidgwick e, mais perto de nós, R. Hare, A. Hart, J. C. Smart, John Harsanyi. O utilitarismo assim definido ter- 
se-ia mantido dominante nos países anglo-saxônicos, e especialmente nos Estados Unidos até cerca de 1970 e à publicação da Theory of Justice, de John Rawls. Esta visão oficial das coisas é muito insuficiente. J. Bentham reconhece as suas dívidas para com Beccaria, Helvetius e Hume. Este último inscreve-se na linhagem daquilo a que podemos chamar os moralistas aritméticos, muitas vezes apresentados como os primeiros utilitaristas, Shaftesbury, Hutcheson, Adam Smith. O que é estranho é que talvez não haja mais utilitaristas na história do pensamento, em muitos aspectos, que Shaftesbury e Adam Smith. Pelo menos o Adam Smith da Teoria dos sentimentos morais. Estes últimos escrevem, de fato, para se demarcarem de Hobbes e Mandeville, e da afirmação cínica da realidade do egísmo psicológico. O que levanta o problema, muito complexo, da relação mantida pela filosofia utilitarista, com a afirmação da universalidade do egoísmo, por outras palavras, com a questão de saber se os homens se regem pelo self-interest, pelo self-preference ou pelo self-regarding principle.

A estranheza tem a ver com o fato de, se chamamos utilitarista às teses que postulam que a justiça consiste na maximização da felicidade dos indivíduos egoístas, então as teorias mais utilitaristas são as de Hobbes e de Locke, e, mais geralmente, as do jusnaturalismo. Mais utilitaristas que a teoria do próprio Bentham. Ora, como se sabe, Bentham, na esteira de Hume, revela-se um dos mais virulentos críticos do jusnaturalismo e das fantasmagorias do contrato social. As vias do utilitarismo parecem pois, a priori, relativamente impenetráveis. Não decidamos por enquanto e limitemo-nos a apresentar como utilitarista, no sentido estrito do termo, a versão benthamiana, e como utilitaristas no sentido lato do termo as diversas doutrinas jusnaturalistas modernas, cuja ferramenta intelectual central é representada pela teoria do contrato social. ${ }^{11}$

Para melhor compreender as filiações entre escolas aparentemente opostas, mas freqüentemente complementares, teremos provavelmente de remontar mais longe, até à filosofia antiga. $\mathrm{O}$ fato essencial, de que temos de ter consciência, se queremos situar corretamente o lugar do utilitarismo na filosofia moral e política, é que o primeiro grande pensador utilitarista de todos os tempos é justamente aquele que faz nascer a Filosofia Política, Sócrates, do qual, recordamos, Hegel já estigmatizava o subjetivismo. O utilitarismo de Sócrates é uma evidência 
se atendermos à leitura de um dos seus principais discípulos, Xenofonte. ${ }^{12}$ Mas o testemunho deste último é habitualmente recusado. Dá-se a entender que ele nada teria compreendido das propostas do seu mestre. O testemunho do seu segundo discípulo, infinitamente mais prestigiado, Platão, parece contudo bastar para atestar que todo o pensamento de Sócrates se organiza à volta do sistema de identidades, que ele afirma existir, entre o justo, o verdadeiro, o belo, o bem e o útil pelo qual entende a maximização da felicidade de todos. É a evidência deste critério utilitarista, racionalista, que ele opõe à retórica dos sofistas, e que o incita, tal como os discípulos de Bentham, a denunciar os sortilégios e os disfarces da música e da poesia.

A República de Platão, "a maior obra de filosofia política de todos os tempos", segundo Léo Straus, constitui uma defesa e ilustração das identidades socráticas. Contém todas as variantes possíveis e imagináveis do utilitarismo, incluindo a sua refutação. Com efeito, lá encontramos: uma teoria da medida dos prazeres e dos sofrimentos, aritmética, geométrica ou dialética; uma teoria das relações da harmonização espontânea dos interesses - a que se opera na cidade dos porcos -, e uma teoria da harmonização artificial dos interesses sobre a qual se funda a cidade perfeita, uma refutação do tradicionalismo, do positivismo jurídico e do cinismo, uma revelação da antinomia da razão utilitária normativa, cuja solução suporia a emergência improvável de uma personagem problemática: o legislador-rei-filósofo, único capaz de fundar uma sociedade utilitarista perfeita, mas tanto mais improvável quanto só poderia existir se ele fosse produzido e educado por essa cidade perfeita que ele tem por função fundar e instituir (Caillé,1990).

Abrir-se-ia um vasto campo ao estudo do lugar do utilitarismo na filosofia antiga. Seria necessário mostrar a sua consistência relativa sobre o epicurismo, ${ }^{13}$ o eudemonismo, etc. Mais importante é, talvez, notar que o debate do utilitarismo e do antiutilitarismo se inicia com a crítica de A República de Platão, por Aristóteles. Aristóteles, eudemonista, ${ }^{14}$ aceita plenamente a legitimidade do objetivo da felicidade para os indivíduos, recorre muitas vezes a raciocínios utilitaristas, mas, de resto, inicia uma crítica do utilitarismo platônico sobre dois pontos fundamentais, ao afirmar: 1) que a cidade não se funda na necessidade, 
mas no prazer do ser-conjunto; 2) procurando, através da sua teoria da philia um fundamento interacionista e não utilitarista nem holista, $a$ priori, para a relação social.

Esta observação permite-nos voltar à questão do lugar do utilitarismo na filosofia política moderna (a partir dos séculos XVIXVII). O melhor meio de compreender a sucessão das escolas é partir da distinção feita por Élie Halevy (1903) entre três maneiras de pensar a articulação dos interesses dos indivíduos, estando entendido que o problema é sempre o da relação entre as utilidades dos indivíduos e a soma dessas utilidades: a teoria da fusão dos interesses, a teoria da sua harmonização artificial, a teoria da harmonização espontânea. Do ponto de vista dessas distinções, a verdadeira diferença entre o jusnaturalismo e as teorias do contrato social, por um lado, e utilitarismo benthamista, por outro, não incide tanto sobre a axiomática de base como sobre a representação dos modos da harmonização dos interesses. De fato, jusnaturalismo e utilitarismo benthamiano põem em cena indivíduos que procuram maximizar racionalmente os seus interesses. Um e outro participam na axiomática do interesse. A divergência está na questão de saber como esses interesses individuais racionais são susceptíveis de se combinarem para a formação de uma sociedade harmoniosa.

Simplificando: pode-se dizer que as teorias do contrato social postulam uma harmonização espontânea dos interesses. A teoria econômica do mercado será a principal formação científica dessa intuição, que sustenta todas as teorias do contrato social. Pelo contrário, o utilitarismo stricto sensu, o de Jeremy Bentham, consiste numa teoria da harmonização artificial dos interesses. Uma vez que os interesses não são espontaneamente compatíveis, e é necessário que um legislador racional os combine racionalmente, ou os aperfeiçoe por meio de um manejamento judicioso dos castigos e das recompensas, ou mesmo através da mentira (cf. a nobre mentira de Platão). A questão do lugar ocupado nestas duas correntes de pensamento pelo postulado do egoísmo é complicada, dada a existência de uma terceira corrente de pensamento, a dos moralistas empiristas ingleses, representados por Shaftesbury, Hutcheson, Hume e Adam Smith. Com efeito, esta corrente procura uma terceira via teórica, a que consiste em pensar uma fusão dos interesses através do emprego do conceito de simpatia e a postulação 
do caráter inapto de um sentido moral. Existiria um prazer específico da virtude análogo ao prazer que o comer ou beber procuram.

Continuando a simplificar consideravelmente, digamos que as teorias do contrato social são individualistas, que o utilitarismo benthamiano consiste num holismo de base individualista, e que as teorias da simpatia se inscrevem numa perspectiva interacionista. Se a obra de Bentham, bem como a dos seus sucessores, é tão difícil de desdobrar teoricamente, é porque ela só remata o postulado de egoísmo de Hobbes, passando pelo subterfúgio da sua negação crítica empreendida pelos moralistas ingleses, considerados os "precursores" de Bentham. Existe um vasto debate no mundo erudito sobre a questão de saber em que medida Bentham recorre aos postulado do egoísmo. ${ }^{15}$ A resposta mais provável, já indicada por É. Halévy (1903), é que Bentham o faz progressivamente, à medida que se tornava radical e democrata. O que, diga-se de passagem, levanta a questão das relações entre egoísmo, interesse material e democracia.

Para terminar este quadro, tão atrevido como caricatural, convém ainda distinguir três períodos do utilitarismo normativo: o do utilitarismo tradicionalista, que não distingue claramente o egoísmo do altruísmo, e que defende que a principal motivação dos indivíduos é, ou deve ser, a procura da estima de si e dos outros; o do utilitarismo burguês, que consiste no pleno reconhecimento da legitimidade do egoísmo e do interesse material; o de um utilitarismo que poderíamos qualificar de pós-moderno, cujo primeiro representante importante é Derek Parfit (1984), que deixa de acreditar na existência de um sujeito unificado e homogêneo dos cálculos.

\section{2) A antinomia da razão utilitária normativa}

Que censurar a este utilitarismo normativo, por outras palavras, que censurar ao objetivo da procura da felicidade para todos, que parece impor-se com uma força irresistível? Fundamentalmente, três coisas. ${ }^{16}$

Em primeiro lugar, ele é, em muito larga medida indeterminado, pois que, se nos diz que se deve maximizar a felicidade de $\operatorname{todos}^{17}$ não nos esclarece de que todos se trata. Dever-se-á maximizar a felicidade de todos os membros de uma família, de vários, de uma aldeia, de várias 
aldeias, de uma província, de uma nação, de um continente, do mundo inteiro? E porque não a dos animais, superiores ou inferiores, das plantas, finalmente do cosmos, como o preconizam, de resto, alguns utilitaristas contemporâneos (P. Singer)? A resposta a esta primeira questão implica uma avaliação normativa, que não pode ser deduzida do racionalismo utilitarista. Suponhamos, contudo, que o problema é resolvido. Desembocar-se-ia numa outra dificuldade muito mais difícil de ultrapassar.

Em segundo lugar, não é possível discutir o postulado segundo o qual a justiça consiste na maximização da felicidade dos indivíduos, se não nos disserem nem em que consiste a justiça nem em que consiste a felicidade. Mas o problema central é o de saber como se deve compreender a soma dos indivíduos. Esta soma será equivalente ao conjunto dos indivíduos, ou divergirá desse conjunto? Bentham afirmava claramente que o conjunto não é mais que a soma dos indivíduos. Desse modo, conferia ao utilitarismo uma tonalidade democrática radical, pois que "um não vale mais que um". A comunidade, o Estado ou a sociedade, nesta óptica, são fictitious bodies, sempre decomponíveis, em princípio, nas suas unidades elementares, os indivíduos. E só sobressaem, no fim de contas, o ponto de vista, os prazeres e as dores dos indivíduos empíricos. Mas, se esta posição tem a vantagem do radicalismo e da clareza, ela conduz a consequiências temíveis. De fato, que pode o legislador racional decidir se, e quando, a maioria dos indivíduos deseja unicamente jogar cartas e, sobretudo,, não quer ler nem Platão nem Shakespeare? Nesse caso, conclui Bentham logicamente, não se deve editar nem Platão nem Shakespeare. Uma tal conclusão teria de inquietar os sucessores de Bentham, que procuram remediá-la. Argumentaram, em resumo, que nada permite pensar que os indivíduos empíricos estejam verdadeira e plenamente informados dos prazeres que se lhes abrem e que, por isso, sejam os únicos juizes legítimos do bem, da felicidade ou da infelicidade coletivos. A outra dificuldade é que é racionalmente impossível convencê-los de que deveriam ser justos e virtuosos, isto no caso de o não serem desde a origem. Se, na verdade, a justiça coletiva não consiste em nada mais que a satisfação dos interesses particulares, então ninguém pode ser obrigado a privilegiar a felicidade de todos contra a sua felicidade particular, e cada qual está, a qualquer momento, autorizado a violar a lei, se o puder fazer impunemente, em função dos seus interesses particulares imediatos. 
É essa a razão pela qual todas as doutrinas utilitaristas, com exceção da de Bentham, também ela muito ambígua e incerta, desconfiam profundamente dos sujeitos empíricos, e têm todas elas de pôr em cena um sujeito plenamente informado e racional, o filósofo, em John Stuart Mill, ${ }^{18}$ como já em Platão e Aristóteles, um sujeito informado de todas as possibilidades (J. C. Harsanyi) ${ }^{19}$ um sujeito plenamente autônomo (J. Elster) ${ }^{20}$ ou um sujeito moral antes que ser social (J. Rawls). Mas, afirmar que o verdadeiro juiz dos prazeres e dos sofrimentos não é o sujeito empírico mas o sujeito racional omnisciente é o mesmo que defender que um não vale um, que alguns são mais iguais que outros e, portanto, que o conjunto dos indivíduos é diferente da sua soma. Levanta-se então o problema de saber quem vai decidir sobre a utilidade deste conjunto, que transcende o lugar dos sujeitos empíricos concretos. Quer se queira quer não, o utilitarismo volta assim, e necessariamente, a oscilar entre o "perfeccionismo" e o "intuicionalismo", que era suposto ter por missão ultrapassar. ${ }^{21}$

Em terceiro lugar, todos os utilitarismos, sejam quais forem as diferenças que os separam, devem pressupor que existe, pelo menos, um sujeito plenamente racional e plenamente informado. Nem que seja simplesmente virtual: o sujeito empírico, ele próprio, o sábio, o filósofo, o cidadão esclarecido, o cientista, o juiz ou o legislador, o rei, ou mesmo Deus (cf. Paley, o principal inspirador de Bentham). Ora, sendo um tal sujeito teórico e praticamente inconcebível, o utilitarismo normativo torna-se rapidamente auto-refutante, e tende a oscilar, mais cedo ou mais tarde, para uma teoria da harmonização espontânea dos interesses, através da idéia de que o único sujeito empírico omnisciente que é possível encontrar é representado pelo mercado, dito de outra maneira, pelo contrato e pelo dinheiro. O utilitarismo não é, nesse caso, outra coisa senão o liberalismo econômico vulgar.

Em definitivo, todas as sutilezas, todas as sofisticações e estratégias teóricas que separam as diversas escolas utilitaristas parecem perfeitamente secundárias em relação com as três idéias de força simples, para as quais, implícita ou explicitamente, se é incessantemente reconduzido: 1) a de que a justiça é idêntica à felicidade; 2) que o máximo de felicidade é igual ao máximo de produto nacional bruto (forma moderna da "riqueza" dos economistas de antanho), destinado ao maior número de indivíduos possível; 3) que se deve maximizar a 
quantidade de vida sob todas as suas formas (aquilo a que Derek Parfit chama the repugnant conclusion do utilitarismo).

A conjunção destas três propostas, semi-explícitas, semiimplícitas, deságua num programa de "governamentalidade" (M. Foucault) e de controle social, que permite fazer a economia do debate ético e político, uma vez que o único objetivo sensatamente atribuível à humanidade é o da acumulação indefinida do poder econômico, estatal, técnico e científico. Será possível ultrapassar estas aporias do utilitarismo normativo e procurar, para a justiça e para a questão dos fins do homem e da sociedade, outros fundamentos normativos?

\section{Um outro paradigma possível: a dádiva}

Digamos as coisas de maneira ligeiramente diferente.

O utilitarismo lato ou stricto sensu, jusnaturalista ou benthamista, tenta pensar os fundamentos da "sociedade dos indivíduos", mas hesita no ponto de saber se se deve pensar do ponto de vista dos próprios indivíduos ou do ponto de vista da totalidade que eles formam, o da sociedade. Perante esta questão, o utilitarismo está dividido, teórica e normativamente, entre um momento individualista e um momento holista, que parecem antitéticos e inconciliáveis. Parece que, para ir mais longe, ele deveria seguir uma terceira via, uma via intermédia, que evite apresentar os indivíduos como simples produtos, diretos e mecânicos, da totalidade, ou, ao invés, a totalidade como produto simples, direto ou indireto, dos cálculos individuais. Esta terceira via designei-a, ao longo deste capítulo, mais ou menos implicitamente, de interacionismo. Mostrei os seus frêmitos, já antigos nas ciências sociais. Alinhei sob este rótulo Aristóteles e os empiristas morais ingleses, especialmente o Adam Smith da Teoria dos sentimentos morais. Mas os conceitos de philia, de sentido moral e de simpatia, não cristalizaram, não conseguiram trazer à luz do dia um paradigma alternativo ao utilitarismo, porque se mantiveram demasiado vagos, largamente especulativos e desmunidos de um fundamento empírico claro. Ora, parece-me que existe na literatura das ciências sociais uma obra que é susceptível de dar uma clarificação retrospectiva e prospectiva decisiva a estas interrogações: trata-se do Essai sur le don, de Marcel Mauss. 
Sabe-se que este último estabeleceu a universalidade, no seio do mundo arcaico, da obrigação de dar, receber e restituir. Esta obrigação está, ao mesmo tempo, do lado do interesse e do desinteresse, é utilitarista e antiutilitarista, individualista e holista. Por outras palavras, ela não está nem num lado nem no outro, mas é interacionista.

Digamo-lo ainda de outra maneira. A dádiva arcaica, cujas linhas de força principais Mauss faz ressaltar, rege-se por uma dupla oposição paradoxal. Primeiro paradoxo: só é dádiva desde que espontânea, mas esta espontaneidade está sujeita à obrigação. Dizer que a dádiva releva da espontaneidade é dizer que é feita "para nada", por prazer. Ao mesmo tempo, segundo paradoxo, o interesse, demonstra-o Mauss, está sempre presente, mas de uma maneira tal que a sua satisfação passa pelo subterfúgio da sua negação. O erro do racionalismo utilitarista é pretender limitar a dádiva, como todo o tipo de ação, unicamente ao momento do interesse, quando os três outros pólos, o do prazer por um lado, os da obrigação e da espontaneidade por outro, são igualmente reais. A dádiva funda a aliança, é o alicerce das comunidades, mas, dádiva agonística, só o faz na proporção da ameaça que ela encarna, testemunhando o desinteresse material e portanto a liberdade do doador, de poder a todo o momento recair na hostilidade e na guerra. Um retorno, uma contradádiva, é possível, mas num lapso de tempo dificilmente previsível e segundo um montante que nunca é seguro, pois que o que devolve não pode contentar-se com restituir um equivalente, e lhe incumbe dar, por sua vez, provas da sua liberdade e do seu poder, colocando-se ele próprio na posição de doador.

Fundadora de novas relações, iniciadora de algo que não existia antes dela, símbolo da capacidade de dar a vida como de dar a morte, a dádiva introduziu uma desapropriação sistemática e, como tal, procurada entre os efeitos e as causas, testemunhada pelo estado de endividamento generalizado de cada um para com os outros, que faz com que as contas nunca estejam saldadas e ninguém se possa considerar desobrigado. Neste sentido, ela representa um desafio permanente ao princípio de razão, desafio material, se for caso disso, à necessidade, desafio à submissão, desafio ao encadeamento mecânico das causas e dos efeitos. Não que os ignore, mas entende mantê-los a um nível subordinado, o das coisas que não fazem sentido por si mesmas, tal como mantém a troca por troca, o gimwali, num lugar subordinado e desprezível face à troca cerimonial. 
Por esta razão, o princípio de razão é incapaz de dar conta da essência da dádiva, dado que esta é justamente a procura de algo que está além do princípio de razão suficiente, procura de razões em excesso. Heidegger nota que o princípio de razão, segundo o qual nada é sem razão, nihil sine ratione, esse princípio que Leibniz qualificava de principium magnum et grande et nobilissimum, não é outro que o principium reddendae rationis, o princípio segundo o qual é preciso explicar a razão. Por que e a quem deve ela ser explicitada? - pergunta Heidegger (1962, p. 249).

É, pode-se pensar, no vocabulário e na sintaxe da tripla obrigação de dar, receber e restituir, explorada empiricamente por Mauss, e não de maneira especulativa e a priori, que se devem tentar reformular as grandes alternativas à razão utilitária exploradas pela tradição filosófica, e que nunca chegaram a encontrar o seu denominador comum. Repensar a philia aristotélica, a amicitia ciceroniana ou senequiana; a simpatia dos empiristas ingleses, essa reciprocidade espontânea; o dever moral de Kant, na medida em que ele encarna uma força da obrigação que, por ser obrigação da razão, não deixa de ser irredutível à homogeneidade das causas e dos efeitos. Repensar, finalmente, o estatuto da vida, essa alternativa maior oposta ao utilitarismo por todos os grandes pensadores do final do século XIX e começo do XX, Nietzsche, Guyau, Bérgson, Simmel ou Scheler. Porque a obrigação de dar, na sociedade selvagem, é, antes de mais, obrigação de dar mulheres que dão filhos, obrigação pois de dar a vida, essa centelha de realidade que excede as suas causas.

Tomar verdadeiramente a sério o Essai sur le don, tirá-lo do seu gueto etnológico, para reconhecer nele uma das obras maiores da ciência social, permitiria ultrapassar alguns dos seus becos sem saída, tanto cognitivos como normativos - desde que se vença a timidez de Marcel Mauss -, e mostrar que a dádiva não diz somente respeito aos selvagens, mas é ainda constitutivo daquilo a que poderíamos chamar a sociedade primária moderna.

No plano cognitivo: para compreender o que está em jogo, devemos lembrar que as ciências pretendem tudo explicar em termos de interesses, seja pelos interesses econômicos, seja pelos interesses de poder, ou mesmo pelos interesses sexuais. Dito de outra forma, elas pretendem explicar o todo da ação social de acordo com a lógica do mercado ou com a lógica do Estado. Mas, mercado e Estado não 
representam, de uma certa maneira, mais que superestruturas. Por mais importantes e dominantes que sejam nos nossos dias, elas são da ordem da socialidade secundária. Ora, ainda hoje, sob a socialidade secundária, e por vezes até no seu centro, subsiste uma importante socialidade primária, aquela que estrutura a aliança e o parentesco, a camaradagem e a amizade, a vida associativa. Defendo a hipótese de esta socialidade primária ser o lugar das relações de pessoa a pessoa e de estas funcionarem ainda de acordo com a obrigação de dar, receber e restituir. ${ }^{22}$

No plano normativo: desta constatação empírico-teórica decorrem talvez implicações normativas importantes. Para as medir, basta refletirse sobre a experiência das comissões de ética francesas. Elas opõem-se massivamente tanto ao utilitarismo prático como ao utilitarismo normativo anglo-saxônico. Concretamente, recusam toda a venda ou aluguel de esperma, de sangue, de ventres ou de órgãos diversos, só aceitando a sua dádiva. Mas para esta recusa do contrato, do intermediarismo monetário, tal como para esse privilégio normativo atribuído à dádiva, elas não conseguem encontrar outras razões que não sejam religiosas ou humanistas vagas. ${ }^{23}$ Parece-me que se se pudesse mostrar que o sentido da relação social primária está ligado à tripla obrigação de dar, receber e restituir, que é através destes três movimentos que se tecem as comunidades, especialmente a família, e que se formam as identidades pessoais, então haveria matéria para encontrar um fundamento, simultaneamente racional e empírico, para a recusa da venda daquilo que toca à pessoa humana e para o privilégio reconhecido à dádiva.

É verdade que a relação social que forma a grande sociedade não se reduz à sociedade primária nem às relações de pessoa a pessoa, e que a regra que vale para a sociedade primária não pode valer, tal e qual, nem para o mercado nem para o Estado. Subsiste assim o problema de saber em que fundar a justiça na grande sociedade, dado que ela é irredutível às pequenas sociedades que tecem as relações de dádiva (distinção particularmente bem vista por Hume e Bergson). O problema é vasto, e não conheço nenhuma resposta a priori para ele. A única coisa que parece clara é que o funcionamento da ordem democrática supõe um mínimo de virtude nos cidadãos, e amizade, philia, entre eles, e que está excluído que a virtude possa nascer unicamente dos 
cálculos utilitários, mesmo que moralistas e altruístas, dos cidadãos ou dos seus dirigentes. Resta-nos assim pensar numa philia e numa obrigação de dar, receber e restituir em escala de grandes números. Um tal pensamento implica que se procure para a ordem democrática um outro fundamento, imaginar que não seja propriamente político? Nesta primeira parte, verificamos como o modo de conceitualização dominante nas ciências sociais as conduzia ao esquecimento da essência política das sociedades. O que agora temos de fazer é tentar a reconquista de uma interrogação do político.

\section{Notas}

1 Dupuy, F. Eymard-Duvernay, O. Favereau, A. Orlean, R. Salais e L. Ihévenoi, os autores do número especial da Revue Économique (v. 40, n. 2, mar.1989), que apresenta as teses da nova escola, concordam com a idéia de que "a admissão de uma convenção comum não deve conduzir à renúncia dos preceitos do individualismo metodológico" (p. 143).

2 Cf. Sperber e Wilson, 1989.

3 A melhor crítica da teoria econômica neoclássica, a que mais luz sobre a impotência que nela resulta da sua recusa arrogante do empirismo, parecenos ser a de Mark Blaug na sua Méthodologie économique (1987). Pode lerse uma excelente crítica das versões recentes da teoria do equilíbrio geral em Bernard Guerrien,"La théorie néoclassique Bilan et perspectives du modèlé d'équilibre general", Econômica 89; cf. igualmente B. Guerrien. "Mythes et réalitês de la théorie économique", Revue du MAUSS, Paris, n. 9, p. 123147, $3^{\circ}$ trim. 1990, e também La théorie néoclássique (Paris, La Découverte, 1989), da coleção "Repéres". O caráter tautológico e circular da teoria do equilíbrio geral tinha sido perfeitamente revelado, já em 1947, por Bertrand Nogaro, num livro injustamente desconhecido e esquecido: Le valeur logique des téories économiques (1947). Foi nesta mesma circularidade que nós mesmo insistimos, em "La rationalité économique n'existe pas", Bulletin du MAUSS, Paris, n. 13, p. 106-144, mar. 1985, e retomada em Splendeurs et misères des sciences sociales (Genebra : Droz, 1986).

4 Renunciar ao princípio de racionalidade não implica nem desesperar a razão nem renunciar à procura do rigor. É reconhecer que as ciências humanas e sociais não são susceptíveis de caber no molde das ciências da natureza. Elas são o lugar daquilo a que Claude Lefort chama as "obras de 
pensamentos", que ele distingue das obras de arte e das obras de ciência (Les formes de l'histoire. Paris : Gallimard, 1978. p. 141). O mérito do livro recente de Jean-Claude Passeron, Le raisonnement sociologique (Paris : Nathan, 1991), é assumir plenamente esta diferença irredutível sem por isso deixar ir o trigo com o joio, e mantendo uma distância igual da ilusão experimentalista (e racionalista, acrescentamos por nossa conta) e da ilusão hermenêutica.

5 Dagtinn E.; H. Esdal. Le salut des présupposés de rationalité dans l'interprétation et dans l'explication de l'action. In: Neuberg et al., op. cit., p. 175. Jon Elster um dos que foram mais longe na tentativa de mostrar como certos comportamentos, aparentemente irracionais, a fé ou a generosidade, por exemplo, eram susceptíveis de ser explicados como resultados de escolhas racionais iniciais, sendo portanto, de fato, racionais, conclui ele próprio: “A teoria da escolha racional é, primeiro e antes de tudo, uma teoria normativa. Só de maneira muito secundária é explicativa" (Solomonic judgements: studies in the limitations of rationality, op. cit. p. 1).

6 Em 1428, no seu Oratio, Bruni escreve que o lucro bem compreendido é benéfico ao conjunto da República. No mesmo ano, Poggio defende que "o dinheiro representa o nervo vital de uma República e que os homens que gostam de dinheiro são os seus alicerces" (apud Skinner, 1978, p. 74). Em França, tivemos de esperar quase dois séculos para encontrar eco dessas propostas ousadas na pena de Antoine Hotman que, em Les deux paradoxes de l'amitié et de l'avarice (1598, retomado em 1616 em Opuscules françaises des Hotmans), escreve que "o bom prescreve que um homem seja tão rico quanto possível", e que "quem rejeitar as riquezas que nos dão as comodidades da vida é desnaturado e não sabe o que é viver" (apud Rothkrug, 1989, p.104).

7 Sobre este ponto, ver Caillé, La sociologie de l'intérêt est-elle interessante?. Para uma crítica detalhada do economicismo denegado de P. Bourdieu, ver Caillé (1992)

8 Sobre a conquista dos departamentos de sociologia americanos pela RAT, ver a excelente informação reunida por Calhoun e Wac-Quant em "La Rational Action Theory aux États Unis".

9 É a conclusão a que chega Jon Elster (1989).

10 A Society for the Advancement of Socio-Economics (SASE) agrupa em torno de personalidades prestigiadas, como Amitai Etzioni, Amartya Sen, Kenneth Boulding ou Albert Hirschmann, centenas de universitários de uns trinta países. Em francês, sobre socioeconomia, ver Revue du MAUSS, n. 9, $3^{\circ}$ trim. 1990. 
11 O caso da Teoria da Justiça, de John Rawls, é particularmente interessante. Ela pretende-se antiutilitarista. No entanto, na sua formulação inicial, apóiase num conceito de racionalidade que, diz-nos J. Rawls (trad. francesa, Paris: Seuil, 1987. p. 40), “deve ser interpretado, na medida do possível, no sentido restrito corrente na teoria econômica". A teoria da justiça funda-se, pois, na axiomática do interesse, ou seja, no utilitarismo teórico para refutar o utilitarismo filosófico. Como todas as teorias do contrato social, ela é utilitarista lato sensu. O "segundo" Rawls, em contrapartida, mais realmente kantiano (?), reclama-se do sensato, "isto é, da capacidade das pessoas para terem um sentido da justiça" (Rawls, J. Les libertés de base et leur priorité. Critique, p. 439, jul. 1989), com o risco de recair no "intuicionalismo", que ele pretendia antes de tudo ultrapassar. Rompe assim com o utilitarismo teórico, mas sem que isso impeça alguns utilitaristas filosóficos, desejosos, também eles, de responsabilidade kantiana, de o reconhecer como um dos seus. Pomos aqui o dedo na ferida das dificuldades inerentes à articulação entre utilitarismo teórico e utilitarismo normativo. O utilitarismo é uma doutrina com duas faces. Aquilo a que chamamos utilitarismo teórico (a axiomática do interesse), Bernard Williams e Amartya Sen (na sua introdução a Utilitarism and Beyond, 1982) chamam welfarism, e denominam consequentialism àquilo a que chamamos utilitarismo normativo ou filosófico. O utilitarismo, salientam (p. 3), "situa-se na intersecção de dois tipos de teorias diferentes". É pois, escrevem, um welfarist consequentialism (p. 5). Que estes dois tipos de teoria não se harmonizam facilmente, ou que podem entrar em contradição, é o que ressalta do propósito de Philippe Van Parijs, que já citamos, segundo o qual "muito longe de implicar a sua verdade, o utilitarismo como teoria política normativa pressupõe a falsidade do utilitarismo como teoria explicativa do comportamento individual" (Qu'est ce qu'une société juste? Paris, p. 33). Curiosa doutrina que só pode ser verdadeira se for falsa.

12 De Xenofonte, sobre este ponto ver La Cyropédie e Les Mémorables.

13 Jean-Marie Guyau (1985), imputa uma problemática utilitarista não a Sócrates ou ao Platão de Protágoras ou de A República, mas à escola epicuriana, tendendo a mostrar que o cálculo do prazer e do sofrimento que esta desenvolve é idêntico ao dos empiristas morais ingleses de Bentham.

14 Convém distinguir eudemonismo, procura da felicidade, hedonismo, procura do prazer e utilitarismo. A diferença essencial reside no postulado de mensurabilidade dos prazeres e dos sofrimentos que caracteriza o utilitarismo. Qualifiquemos pois de utilitarista toda a doutrina que, identificando a justiça e o bem com a felicidade dos indivíduos, considerados coletivamente, defende que a felicidade se decompõe em elementos mensuráveis - o útil e o agradável, por exemplo, os prazeres e os sofrimentos -, para deduzir deste duplo 
postulado de redutibilidade e de mensurabilidade que a justiça e a felicidade são assunto de ciências e de medida, e, que, reciprocamente, o vício e a infelicidade resultam da ignorância e de um mau cálculo (cf. Caillé, op. cit., p. 71 et seq.).

15 De fato, a primeira fonte da inspiração de Bentham é, sem dúvida, mais francesa que inglesa. Lá, onde os moralistas ingleses do século XVIII consagram todos os seus esforços a contornarem o postulado do interesse egoísta, o conjunto das Luzes francesas desenvolve, sem hesitar, todo o debate moral na base da aceitação da evidência da força do interesse; a única dificuldade tem a ver com a questão de saber o que se deve entender pelo interesse, bem compreendido ou classificado (ver, sobre este ponto, o muito esclarecedor livro de Jacques Domenech, L'éthique des Lumières (1989). Toda a retórica dos revolucionários franceses é profundamente utilitarista (cf. Bouche, 1990). Não esqueçamos que Bentham foi feito cidadão francês honorário pela Revolução.

16 Limitando-nos ao que nos parece fundamental, não entramos no debate técnico ligado ao utilitarismo filosófico antigo, irrigado por um número muito considerável de livros e de artigos, e por isso extremamente denso e complexo. Não cuidamos aqui, por exemplo, das diferenças entre "act" e "rule" utilitarism, nem da questão de saber se, de um ponto de vista utilitarista, mais vale maximizar a utilidade média ou total. Sobre o utilitarismo normativo, a melhor exposição em francês é a Philippe Van Parijs (op. cit.,capítulo 2). Não entramos também na discussão sobre a dimensão sacrificial do utilitarismo (será preciso lançar cristãos aos leões para aumentar a soma dos prazeres do proletariado romano?). Em Le sacrifice et l'envie, Jean-Pierre Dupuy (1992) critica a doutrina de Rawls, por nada ter a dizer sobre as situações sacrificiais e por não conseguir ultrapassar o utilitarismo por essa razão precisa. O maior erro do utilitarismo residirá na sua incapacidade de coordenar a lógica sacrificial, ou na sua dificuldade em fugir à axiomática do interesse que o fez nascer? Este segundo ponto parece-me mais importante. De resto, nas críticas que dirige não já a Rawls mas a Hayek, a Nozick ou aos anarco-capitalistas, é esta última dimensão do utilitarismo que Dupuy privilegia.

17 Para simplificar, tomamos aqui "todos" como aproximação do "maior número" benthamiano.

18 O filósofo, segundo John Stuart Mill (1968), goza de prazeres qualitativamente superiores aos do indivíduo normal. Por isso, ele é juiz único da utilidade verdadeira, que Stuart Mill distingue do "expediente".

19 J. C. Harsanyi toma como critério de decisão não as preferências empíricas dos indivíduos mas as suas "verdadeiras" preferências, pelas quais ele entende 
as preferências que eles teriam (itálico de J. C. Harsanyi) se dispusessem de toda a informação pertinente, raciocinassem sempre com o maior cuidado, e estivessem um num estado de espírito particularmente propício à escolha racional (J. Harsanyi, "Morality and the Theory of Rational Behavior", 1982).

20 Jon Elster, por sua vez (em "Sour Grapes", artigo traduzido no Bulletin du MAUSS, 1982), propõe que se retenha na função de escolha social coletiva unicamente as necessidades que procedem da autonomia do sujeito e que vão no sentido do seu reforço.

21 No perfeccionismo ele defende que existem valores eminentes, a priori (por exemplo o prazer do filósofo, a autonomia, etc.), que primam sobre todos os outros, e ao cumprimento dos quais os outros devem ser sacrificados. No intuicionismo ele pressupõe que um sentido moral pré-existe às escolhas racionais e nelas se mistura inextrincavelmente. Mas, em ambos os casos o utilitarismo torna-se inútil e redundante, pois que o seu objetivo inicial era justamente, deduzir os valores e a moralidade desejáveis em vez de os pressupor (estes conceitos de perfeccionismo e de intuicionismo devem-se a J. Rawls).

22 Estas hipóteses são desenvolvidas em L'ésprit du don, de Jacques Godbout (em colaboração com Alain Caillé), 1992.

$23 \mathrm{E}$ a dádiva a que elas evocam é, de fato, largamente atravessada por preocupações mercantis e estáticas. A dádiva gratuita do sangue alimenta os grandes laboratórios industriais que, esses, procuram a rendibilidade no mercado internacional. Viu-se recentemente até que ponto a preocupação estática de preservar a rentabilidade mercantil vinha interferir com o sistema da doação de sangue. Um bom tema para os utilitaristas estudarem: a preocupação de preservar as hipóteses de concorrência da investigação francesa justificará o risco de algumas centenas ou de alguns milhares de mortos? Aliás, a lei Caillavet (1976), ao considerar, salvo prova ou testemunho em contrário, qualquer pessoa acabada de morrer como doadora dos seus órgãos, tende a fazer da doação de órgãos, mais que uma dádiva verdadeira, uma forma de imposto disfarçado ou virtual. Sobre as ambigüidades da doação de órgãos ver "Bioéthique, ville, citoyenneté", artigo publicado nos Cahiers du LASA, n. 15-16, 1992, segunda parte.

Abstract. In this article, it's demonstrated how certain notions derived from the Rationalism and utilized in Social Sciences are strongly determinated by the utilitarian tradition and, therefore, the very concept of rationality, in practice, bears uncertain limits given its subordination to the concept of interested calculation. Criticism aiming at the utilitarian 
rationality is complex as far as different meanings for utilitarism are at stake: a practical level, such as the economical utilitarism preaching the satisfaction of primary and egoistic material interests; a theoretical level, proposing that all human beings are, by nature, egoistic and calculators; and normative level, creating a tie between Justice and the satisfaction of a huger number of individuals. Criticism to these thesis leads the author to remind Marcel Mauss contribution to settle a new paradigme based on the concept of donation. Mauss' text is a fundamental one to understand the passage of a antiutilistarist negative criticism to another antiutilitarist positive criticism, supported by this new paradigme.

Résumé. Dans cet article, on cherche à demontrer que les notions de raison utilitaire dans les sciences sociales sont bien determinées par la tradition utilitariste et que, par conséquent, dans la pratique, le concept de rationalité connaît des limites donnés para sa subordination au calcul interessé. Mas la critique à la rationalité utilitariste est complexe car il existe différentes registres de l'utilitarisme: celui pratique, par exemple le cas de l'utilitarisme economiste qui propose la satisfaction première des intérêts egoistes materiaux; celui théorique, d'après lequel l'être humain est égoiste par nature; et celui normatif qui relie l'idéal de justice à la satisfaction du plus grand nombre. La critique aux thèses utilitaristes mène l'auteur à rappeler la contribution de Marcel Mauss pour la fondation d'un tiers paradigme, celui du don. Enfin, ce texte est décisif pour que l'on puisse comprendre le passage d'une critique antiuilititariste negative pour une autre, antiutilitariste positive, qui se fonde sur la création du nouveau paradigme.

\section{Referências bibliográficas}

BOUCHE, Jean-François. De l'utilité dans la Révolution. Revue du MAUSS, Paris, n. 8, p. 142-162, $2^{\circ}$ trim. 1990.).

CAILlÉ, A. Esquisse d'une critique de l'économie de la pratique. Cahiers du Lasa, Universidade de Caen, n. 8-9, p. 103-214, $1^{\text {o }}$ sem. 1988; reeditado em Cahiers du Lasa, n. 12-13, 1992.

. Le juste, l'utile et l'agréable: l'utilitarisme dans La Republique de Platon. Revue du MAUSS, n. 6, p.69-96, 4 trim. 1989; n. 7, p. 127-151, $1^{\circ}$ trim. 1990.

DAVIDSON, Donald. Paradoxos de l'irrationalité. Paris : L'Éclat, 1991.

DOMENECH, Jacques. L'éthique des Lumières. Paris : Vrin, 1989. 
DUPUY, Jean-Pierre. Le sacrifice et l'envie. Paris : Calmann-Lévy, 1992.

ELSTER, Jon. Les raisins verts: 1'utilitarisme et la genèse des besoins. Bulletin du MAUSS, n. 6, p. 9-41, 2. trim. 1983.

ELSTER, Jon. The cement of society. Cambridge : Cambridge University Press, 1989.

. Ulysses and the sirens: studies in rationality and irrationality. Cambridge : Cambridge University Press, 1979.

FRANKFURT, Harry. Freedom of the will and the concept of a person. The Journal of Philosopby, n. 68, p. 5-20, 1971.

GAUTHIER, David. Morals by agreement. Oxford University Press, 1986.

GODBOUT, Jacques; CAILLÉ, Alain. L'esprit du don. Paris : La Découverte, 1992.

GUYAU, Jean-Marie. La morale d'Épicure et la morale contemporaine. Paris, 1985.

HALÉVY, Élie. La formation du radicalisme philosophique. 1903.

3 tomos.

. La formation du radicalisme philosophique. Paris : Alean, 1903.

HARSANYI, J. C. Morality and the Theory of Rational Behavior. In: SEN, Amartya; WILLIAMS, Bernard. Utilitarism and Beyond. Cambidge : Cambridge University Press, 1982.

HEIDEGGER, Martin. Le principe de raison. Paris : Gallimard, 1962.

MILL, John Stuart. L' utilitarisme. Paris : Flammarion, 1968.

MOSER, P. K. et al. Rationality in action: contemporary approaches. Cambridge University Press, Nova York, 1990.

NEUBERG, Marc. La théorie de l'action: textos majeurs de la philosoplue analytique de l'action. Liége : Mardaga, 1991.

PARFIT, Derek. Reasons and Persons, Clarendon Press, Oxford, 1984.

SCHELER, Max. Nature et formes de la sympathie, 1913. Paris : Petite Bibliothèque Payot, 1971.

SIMON, Herbert. Models of bounded rationality. Cambridge, Mass : MIT Press, 1982.

SPERBER, Dan; WILSON, Deirdre. La pertinence. Paris : Minuit, Paris, 1989. VAN PARIJS, Philippe. Qu'est ce qu'une société juste? Paris : Seuil. 